\title{
Cycles in basic innovations
}

\author{
Bert de Groot* \\ Econometric Institute Erasmus University Rotterdam \\ Philip Hans Franses \\ Econometric Institute Erasmus University Rotterdam
}

Econometric Institute Report 2005-35

\begin{abstract}
Basic innovations are often believed to be the drivers of economic growth. It has been widely documented that economic growth follows cyclical patterns of varying length. In this paper we examine if such patterns are also present in basic innovations. For an annual time series of count data covering 1764-1976, we fit a harmonic Poisson regression model. The results suggest the presence of multiple cycles of length 5, 13, 24, 34 and 61 . We compare these cycles and their joint effect with widely documented economic cycles and find important resemblances and differences.
\end{abstract}

Keywords: Economic cycles, Basic innovations, Poisson regression, harmonics

${ }^{*}$ Address for correspondence: Econometric Institute, Erasmus University Rotterdam, P.O.Box 1738, NL-3000 DR Rotterdam, The Netherlands; e-mail: edegroot@few.eur.nl. The Eviews programs used for all calculations in this paper can be obtained from the authors. 


\section{Introduction}

Radical innovations play a central role in almost all long wave theories. Protagonists of the view that economic development is explicitly driven by radical innovations are for example Schumpeter, Mensch and van Duijn, where Schumpeter was the first to conjecture that economies are driven by entrepreneurial innovation. ${ }^{1}$ Economic development is assumed to depend on the ability of heroic entrepreneurs who combine exogenously produced scientific inventions and original ideas to create "new combinations", which then lead to a cluster of basic innovations which in turn will propel new leading sectors.

Mensch elaborated on this notion and added the idea that the clusters of radical innovations develop during depression periods because only then, companies would be desperate enough to try to rekindle profitability through investing in radical new technologies. Clark, Freeman and Soete refuted Mensch's depression trigger hypothesis and argued amongst other things that basic innovations cluster mostly in the beginning of the long wave upswing. Van Duijn combines principles from the innovation literature with investment theory and focuses on innovation life cycles. He states that new radical innovations with the help of a conducive investment climate create new industries which are able to take the economy to a higher level of development. Supporters of the investment school and the Marxists thought innovations only to be supportive in their respective theories.

In the present paper we also focus on innovations, and we examine the link between bursts of radical innovations and economic cycles. Indeed, there is ample evidence of the such cycles in economic data. Since the debate on long waves really took off after Kondratieff's somewhat controversial publications (1925), many authors have devoted time and energy to question and examine "the long wave". This line of research resulted not only in findings on the long wave with a duration in between 40 to 60 years, but also other waves with different lengths and also different drivers were found. The well known cycles of Kitchin (1923), Juglar (1862) and Kuznetz (1930) are just a few examples. The

\footnotetext{
${ }^{1}$ Full reference to the relevant publications will be given in later sections, where we concisely review the literature.
} 
length of the various cycles found in terms of the critical literature of "the long wave" seems to cluster around certain averages. In the present paper we give a condensed historical overview of the findings of authors who have studied innovations and long wave related theories.

The main focus in our paper is to examine the link between innovations and economic cycles by studying cyclical patterns in innovations. For that purpose, we first start in Section 2 with a review of the literature on the link between innovations and long economic cycles. Next, in Section 3, we concisely summarize the literature on economic cycles by providing a table with the main landmark results. In Section 4, we analyze a time series with count data concerning basic innovations. We propose a harmonic Poisson regression model for this purpose and test for the presence of multiple cycles. We find compelling evidence of such cycles of length $5,13,24,34$ and 61 years. We provide a graph of their joint cyclical pattern and compare this pattern with the Kondratieff cycel. In Section 5, we conclude our paper by formulating a few conjectures that provide interesting areas for further research.

\section{Innovations and long cycles}

In this section we summarize the main arguments for the presence of a relation between economic cycles and basic innovations.

\section{Schumpeter and Kuznets}

In his book Business Cycles (1939), Joseph Schumpeter developed the entrepreneurial model of innovation in which skilled individuals use exogenously produced inventions and original ideas to create "neuer Kombinationen". These radical innovations are distributed randomly over time. A cluster of basic innovations is assumed to create a new and fast growing leading sector in the economy, which facilitates an upswing in the long wave. Innovators who have successful applications are considered able to exploit a temporary monopoly. In contrast, radical innovations are discouraged during the upswing because existing technologies already generate ample earnings. Next, after some period of time, 
a swarm of imitators saturates the market, and consequently, margins will erode and earnings will diminish. By then, economic development will slow down and the long wave will enter the down swing phase. In Schumpeter's view, the economy is dependent on heroic entrepreneurs to get out of the depression periods. ${ }^{2}$

Schumpeter's ideas have been criticized along various lines. Kleinknecht (1990) summarizes the most important critiques that appeared in Kuznets (1940) in his, otherwise predominantly positive, review of Schumpeter's book on business cycles. First, Schumpeter was considered to have failed to give evidence that long waves are not merely a price phenomenon, but also exist in real indicators of general economic activity. Second, Schumpeter's explanation of the long waves required a clustering of radical innovations, and this had not been substantiated with empirical data. And, third, Schumpeter had failed to give a convincing explanation of why such clusters would occur. Freeman and Louça (2001) respond that, due to additions and adaptations to the original ideas of Schumpeter in various articles and books, the original critiques can now be refuted and that the notion of the clustering of innovations is now well established.

\section{More on the clustering of innovations}

Mensch (1975) concluded that clusters of radical innovations develop during the end of the long wave down swing. He formulated a theoretical explanation for this phenomenon, the so-called "depression trigger" hypothesis. Mensch distinguishes basic innovations, improvement innovations and pseudo-innovations. Instead of the idealized sinus wave pattern, Mensch uses an S-shaped representation of the long wave in his metamorphosis model. A cluster of basic innovations, which arises at the end of the downswing phase, facilitates the development of a new "S". Clustering is caused by fast imitation, the so-called bandwagon effect. The economy will form itself after the new leading sector and gets into a lock-in. Firms, by then, only want to protect their market shares and

\footnotetext{
${ }^{2}$ Later in his prolific scientific career, Schumpeter abandoned the idea that innovation is solely depending on the creative efforts of individual entrepreneurs. He observed that the bulk of innovations did no longer stem from small entrepreneurial firms but that they were produced by large corporations who relied on the efforts of their $\mathrm{R} \& \mathrm{D}$ departments.
} 
will limit themselves to the improvement of innovations. Firms will desperately try to prevent complete stagnation with pseudo-innovations when market saturation kicks in and the possibilities for new applications of the technology are exhausted. The lack of profitability assures that, despite the higher risk and pessimism associated with the depression phase, investors will change to new radical projects. According to Mensch this is the only way a society can defeat a period of technological stalemate.

A little later, Clark, Freeman and Soete (1981) find much weaker support for the clustering hypothesis than Mensch did. They conjecture that clustering of basic innovations occurs throughout an entire long wave cycle and most predominantly at the beginning of the upswing phase. Furthermore, they also indicate that the timing of the emergence appearance of basic innovations is of no direct importance but it is the moment of diffusion that is essential. Clark, et al. (1981) point out that the diffusion of a group of revolutionary innovations does not proceed directly after they have been introduced but that it can take many years before a cluster breaks through. Moreover, they indicate that the diffusion process is not just copying an innovation, but merely that it consists of a series of further improvements.

Van Duijn (1983) analyzes diffusion, that is, the large-scale distribution of innovations, which he believes is the dominant force behind the long waves. His theory is based on three basic principles, which are innovation, innovation life cycles and investments in infrastructure. Innovations and innovation life cycles are the boosters of the growth process, which additionally is strengthened by investments in the infrastructure. Van Duijn does not assume a univocal link between the long wave phases and the innovation life cycles, and therefore innovations occur continuously. He distinguishes four different types of innovations, that is, important product innovations which create new industries, important product innovations in existing industries, process innovations in existing industries and, finally, process innovations in basic sectors (such as oil refineries and the steel industry).

Finally, in Freeman (1996) and Perez (1983, 2002), the authors take a further step by making the allegation that clusters of basic innovations play a far-reaching part in society. It is emphasized that this is due to the mutual dependency of technical, economic, 
political and cultural factors. Certain types of technological change influence all sectors of the economy. The diffusion of their so-called techno-economical paradigm is accompanied by a large crisis of structural adjustment. Social and institutional change is necessary to bring about a better match between the new technology and the old political, social and management system of the economy, the so-called socio-institutional framework. When such a match is achieved, a relatively stable pattern of long-term investment behavior can emerge that can hold out for about 20 to 30 years, as it is claimed.

\section{Summary}

Long wave researchers such as Schumpeter, Mensch, van Duijn, Freeman and Perez have, each in their own way, provided arguments how basic innovations could correlate with economic development. Schumpeter has been the first to point out the dominant role of the individual entrepreneur in the innovation process, but later he was known to switch to the idea that large corporate $\mathrm{R} \& \mathrm{D}$ departments were responsible for the development of new technologies. Mensch further developed the early ideas of the Schumpeter. He created his depression trigger hypothesis, which was later supported by Kleinknecht but criticized by Clark, Freeman and Soete. The latter authors argued that innovational clustering predominantly takes place during the recovery period. Van Duijn elaborated on the role of investment in the innovation process. Finally, Freeman and Perez enlarged

the focus of the innovation school and incorporated the institutional environment in their analysis.

The basic notion in all these theories is the same. Innovations are important drivers of economic growth and of economic cycles. In the next section we turn our focus to the nature of such cycles.

\section{Economic cycles}

In this section we summarize the relevant literature on the presence of cycles in economic data. We observe that there is a variety of cycles. A concise overview will be given of the various cycles discussed in the critical long wave literature. 


\section{Theory-based cycles}

In the long wave literature, five different economic cycles have been discussed at length. The so-called Kitchin, Juglar, Kuznets, Kondratieff and the Hegemony cycles will be discussed concisely. Other researchers have also found cycles by using a technical analysis of the data, but these have a less well developed theoretical background. Other authors have discovered cycles in non-economic variables. We address these below, though briefly.

The Kitchin stock cycle was discovered in 1923. Kitchin found a pattern of fluctuations that lasted for about 3 to 4 years. He explained these fluctuations by stating that after a recession, firms had too little stocks of raw materials, parts, half fabricates and final products. While aiming to get their stocks at an acceptable level, firms create a demand that influences the entire economy. Demand increases until the firms find out that their expansion has been too exuberant and their stock has become too large. In order to diminish the excess stock, firms will cut back on their stock orders and will lower their output. This can drag the economy into a recession.

The Kitchin cycle is viewed as an endogenous cycle (Tylecote, 1992). There has been relatively little criticism on this as there has always been much empirical support for this cycle. Tylecote conjectures that it is unlikely that the cycle still exists in its original form. Furthemore, Tylecote refers to the 4-year presidential cycle which matches well with the length of the original Kitchin cycle.

Juglar (1862) discovered cycles with length varying between 7 and 11 years. This cycle is now commonly known as the "ordinary medium term business cycle". In his 1862 book "Des crises commerciales et de leur retour periodique en France, en Angleterre et aux Etats-Unis", he wrote that the cycles was not the consequence of forces from outside of the economy but from the inside, hereby indicating that there must be an endogenous explanation. Juglar discerned three stages in his cycle, that is, a period of progress, of crisis, and of liquidation. He did not formulate an explicit theory, but he did present historical and statistical data. His methods formed the basis for later statistics-based approaches.

The third relevant cycle is the Kuznets cycle. It is widely accepted by economists as 
there is sufficient data material. The cycle is related to investments in construction and it lasts for about 15 to 25 years. Kuznets suggested that US population growth, with its large immigration ratio between the 1870s and the 1920s, caused fluctuations in the construction of houses and investments in the railways. ${ }^{3}$

Long waves or Kondratieff cycles are surges in economic development that last for about half a century. They have been studied extensively by many authors from different theoretical backgrounds. This diversity has led to the development of a variety of schools of thought, which all see different drivers of this long cycle. The most important schools are (1) the Marxist capitalist crisis school (Mandel, 1995) which sees the falling rate of profit as the cause of the long cycle, (2) the investment school (Kondratieff, 1925 and Forrester, 1977), which focuses on investment as the main determinant, (3) the innovation school (Schumpeter, Mensch) which puts innovation at the core and (4) the institutionalists (Freeman, Perez) who believe that the interaction between the institutional environment, infrastructure and clusters of basic innovations is the driving force of the Kondratieff wave. Some long wave authors have created a hybrid theory which combines elements from different schools of thought. Van Duijn (1983) and Rostow et al. (1979) each in their own way merge ideas from the investment school and the innovation school. Innovation, though obviously not the main driver in each theory, does play an important part in all proposed long cycles mechanisms.

A range of variables has been examined to provide empirical support for long cycles. The seven main categories are prices, production, innovation and invention, capital investment, trade, real wages and working class behavior, and war. The listed variables differ in availability and quality, as, of course, the data must be investigated over a long period of time. A question of typical interest is whether lengthy cycles can only be found in price and other monetary variables or whether it can also be observed for real variables.

Empirically, the Kondratieff wave is still mostly a cycle in prices. The fact that some important questions surrounding the Kondratieff cycle are yet to be resolved has made

\footnotetext{
${ }^{3}$ The exogenous explanation of the cycle which encompasses the emigration from Europe to the US has been debated. Indeed, did migration cause the upswing or was the cycle already in upswing and did the arisen expectancies trigger the immigration flow?
} 
this long cycle somewhat controversial. However, the approaches, which focus more on the diffusion of clusters of basic innovations and their assimilation within society, may lead to new insights on the Kondratieff cycle.

Finally, Goldstein (1988) gives an overview of long wave and hegemony (war) cycles. He divides the hegemony debate in three distinct schools of thought. These are the leadership cycle school (Modelski, 1978), the world system school (Wallenstein, 1983) and the power transition school. Modelski's leadership cycle school does not describe war cycles, but it analyzes political cycles in which the institutions and regulations arise on the basis of which international contacts take place. This leadership cycle school eventually distinguishes twenty long waves. Alternatively, Wallerstein's world system school has neo-Marxist roots and mostly examines the relationship between core and periphery, in contrast to the other schools which mainly look at conflicts within the core of the world system. Finally, the power transition school follows the work of Organski (1958) and it states that an international hierarchy is necessary to prevent war. A super power must intimidate potential challengers in such a way that war is not a real option for them anymore. Modelski's (1978) leadership cycle school finds hegemony cycles with a length of 100 years, while Wallerstein's (1983) world system school distinguishes a 150 year hegemony cycle.

Goldstein (1988, p. 283) makes a distinction between the long wave in war, which he incorporates in his Kondratieff theory, and an autonomous longer wave in hegemony. He follows Wallerstein's conclusions and accepts the 150 year hegemony cycle.

\section{Data-based cycles}

Various researchers have found many different cycles through a data-based examination of data on available economic or other indicators. Although there is no theory, several studies do appear in the literature and deserve some mention.

Kuczynski (1978) discerned cycles of 2, 8, 9, 13, 23 and 60 years, see also van Duijn (1983, pp 170-171). Kuczynski focussed on real economic growth of production and also

used inventions and innovation data. Using spectral analysis he found a variety of waves 
with different lengths. He could not explain the theoretical background of his findings.

Haustein and Neuwirth (1982) report cycles of length 7, 9, 13, 20, 32 and 40 years. Haustein and Neuwirth uses the same data as Kuczynski (1978). Amongst other things, they describe a cycle with length about 32 years from invention to innovation, using different data sets from West Germany, U,K, and the USA. They also find a 20-year cycle in inventions and innovations, and a 13-year cycle representing relationships between innovations and industrial production or energy consumption.

Solomou (1998) reports the following. British GDP seems to have two stochastic cycles of 8.6 and 24.6 years. When a single cycle is imposed, a cycle length of 12.3 years is found. The US economy displays cycles of 5 years, of 10.8 and of 19.2 years. The German economy displays cycles of 10.8 years as well, and also one of 23.8 years. Finally, the French GDP has cycles of length 4.5, 7.7 and about 20 years. According to Solomou, each era has its own unique and not internationally synchronized constellation of cycles.

Forrester's (1977) long cycle originates from a model simulation (the National Model), which he associates with the Kondratieff cycle. His model also implies a so-called bootstrap. A bootstrap structure arises when a sector uses part of its own sales as a production factor. The signal to increase the supply of the factor leads to operations which, at least in the short term, cause a reduction in the supply. This process also takes place in the capital sector. When the capital sector has to increase its supply in order to satisfy an increase in demand, both labor and capital equipment are needed. The only way to facilitate this is by withdrawing investments from the consumption sector, which was responsible for the increase in demand in the first place. Thus a delay arises which ensures a considerable extension of the periods of fluctuations. Haustein and Neuwirth (1982) consider bootstraps to be a well known economic phenomenon. They give an example in the shipbuilding industry with a cycle length of approximately 17 years. According to these authors, Tinbergen proved that the entire cycle length is four times the lag (ibid, p. 68).

Thio (1991) puts forward a model of labour supply and deduces a 32 year cycle.

Howe and Strauss (1991) started from the concept of historical generations, which 
would show a repetition through the centuries. They identify a cohort generation as everyone born within a particular 20-25 year time span. People in a cohort generation have a similar world view. Howe and Strauss delineate 17 different generations over the course of American history between 1584 and 1981 with number 18 starting in 1982 . The socalled four-phase four-generation cohort cycle, where recessive and dominant generations alternate, thus has a length of around 90 years. Berry en Kim (1994) connected the age cohort analysis with the Kondratieff cycle. They combine the four consequent waves of types of generations to the four phases of the Kondratieff wave.

Finally, Namenwirth (1973) used political themes to express the dominant ideology which he then related to the economic situation. He analyzed themes from the political campaigns of the American presidential elections between 1844 and the 1960s and he found cycles of political themes of 48 and even 152 years.

\section{Conclusion}

In sum, there seem to be many causes and drivers for economic cycles of varying lengths. Innovations, certainly, are viewed as of the key drivers, but also other factors exist. In Table 1, we summarize the above reviewed literature.

A final issue concerns the notion that two or more cycles can exist at the same time. Schumpeter was one of the first to think in terms of such a multiple cycle concept. He considered the 'Kitchin' cycle, the 'Juglar' cycle and the Kondratieff cycle. Schumpeter believed that one Kondratieff cycle comprised six Juglars. In turn, the Juglars were composed out of three Kitchin's. He argued that these different waves would operate in parallel because each innovation, the driving forces of the waves had different impact.

The question however is whether any cycle should incorporate an integer number of other cycles. It may well be that various cycles exist at the same time, but that their peaks and troughs rarely, if ever, occur at the same time. For example, if there are two cycles of length 8 and length 13 , only once in the $8 \times 13=104$ years they share an extremum value. In the next section we therefore examine the properties of an innovation count series and look for the presence of cycles. As innovations appear by and large to 
drive economic cycles, it is of interest to see how innovation cycles look like.

\section{Cycles in innovations}

In this section we analyze a lengthy series concerning basic innovations for its cyclical properties. We first put forward three hypotheses, which we derive from the literature review in the previous two sections. Next, we discuss the data, and then the econometric modeling method. We conclude with a description of the results.

\section{Hypotheses}

We have seen that there is a link between innovations and economic cycles. Next, we have seen that there is a variety of long economic cycles. Our first hypothesis $\left(H_{1}\right)$ is then that there are various cycles in innovation data. Following various authors, we next hypothesize $\left(\mathrm{H}_{2}\right)$ that there is a clustering of basic innovations. These two hypotheses can be examined using parameter estimates in the regression model to be discussed below.

Our next hypothesis concern the link between the cycles in innovations, if there would be any, and the economic cycles. Again following the earlier discussion, we propose $\left(H_{3}\right)$ that basic innovations peak where the long wave is at its low point and the number of basic innovations is small where the long wave peaks. Hence, in recession periods at the end of the down swing there are clusters of innovations. Herewith we test again the hypothesis as it was also tested by well-known long wave innovation authors.

\section{Data}

Before the three hypotheses can be tested, the question should be addressed which data set is the most suitable for our analysis.

We decide to rely on the data set created by Silverberg and Verspagen. Silverberg and Verspagen (2000) create a basic innovation super sample by combining the datasets of Haustein and Neuwirth and of van Duijn. Kleinknecht's dataset is not used as it

is too short in comparison to the other two. Silverberg and Verspagen do not apply a weighting procedure because this is not consistent with the use of the Poisson distribution. 
Innovations which exist in both data sets are counted only once in the super sample, just as innovations which appear in only one of the data sets. All innovations are thus treated equal. When there was a difference in the date of appearance of the basic innovation between the sets of Haustein and Neuwirth and Van Duijn there has consequently been chosen for the earliest date. ${ }^{4}$

Silverberg and Verspagen's (2002) innovation super sample involves historically recognized general data set problems such as the end effect error, personal bias of the creator and the fact that in certain cases it is arbitrary whether an innovation is basic or not. Moreover, an important shortcoming of the used data could be that the basic innovations incorporated in all the data set are assumed to be equal whereas in practice the impact on the economy will be different. This is all the more relevant because the long wave theories which have assigned a central role to basic innovations explicitly point out that that certain innovations, whether or not in cooperation with related innovations, have such a large impact they can influence the entire economy. However, the mentioned shortcomings have been widely discussed among the various authors, the data is the best data available for the research as is to be conducted.

The count data we analyze are depicted in Figure 1. It concerns an annual time series of the number of basic innovations per year, and it runs from 1764 to and including 1976, thereby covering 213 years.

\section{The model}

We now say a few words about the Poisson regression model that we use for describing the data in Figure 1.

Consider the variable $Y_{i}, i=1, \ldots, N$ which can take only the discrete values $0,1,2,3, \ldots$ If the variable $Y_{i}$ has many different values relatively far away from zero, the Linear Re-

\footnotetext{
${ }^{4} \mathrm{By}$ focusing on basic innovations and using this data set we are aware that we choose to investigate basic innovations rather than diffusions. All data sets reflect the moment of introduction of basic innovations. It might be that the moment of diffusion is more important for long wave take-off. This has been indicated before by Freeman, Clark and Soete (1982) in their criticism of Mensch (1975) and has later been further developed by Perez (2002) who explicitly based her long wave scheme on the diffusion of the successive technological revolutions. Recently, Hirooka (2003) follows the same approach.
} 
gression model is often used as a good approximation. However, if the number of different realizations in $Y_{i}$ is small as in our case with values ranging from 0 to 8 (which is the maximum amount of innovations in a year in our sample), and the values of $Y_{i}$ are close to zero, this model does not seem to be appropriate as it is unlikely that a possibly continuous variable $x_{i}$ is mapped on the discrete variable $Y_{i}$.

Therefore, we assume that $Y_{i}$ is Poisson distributed, that is, $Y_{i} \sim \operatorname{POI}(\mu)$

$$
\operatorname{Pr}\left[Y_{i}=j\right]=\frac{\exp (-\mu) \mu^{j}}{j !}
$$

for $j=0,1,2, \ldots$ with $\mu>0$. The mean and variance of $Y_{i}$ are given by

$$
\mathrm{E}\left[Y_{i}\right]=\mu \text { and } \mathrm{V}\left[Y_{i}\right]=\mu \text {. }
$$

To translate this unconditional model to a conditional model that is useful for our purposes, we assume that

$$
\mu=\exp \left(\alpha_{0}+\alpha_{1} t+\sum_{i=1}^{C}\left[\beta_{1, i} \sin \left(\frac{2 \pi t}{C_{i}}\right)+\beta_{2, i} \cos \left(\frac{2 \pi t}{C_{i}}\right)\right]\right)
$$

which is a harmonic Poisson regression model. In words, this model says that basic innovations show a trend and cycles of length $C_{1}, C_{2}$ and so on. The amount of cycles is $C$.

\section{Empirical method}

An important empirical decision to be made is the amount of cycles that can be discovered in the data. We decide to take the following strategy. In a test regression we set $\mu$ at

$$
\mu=\exp \left(\alpha_{0}+\alpha_{1} t+\left[\beta_{1} \sin \left(\frac{2 \pi t}{C_{i}}\right)+\beta_{2} \cos \left(\frac{2 \pi t}{C_{i}}\right)\right]\right)
$$

where $i$ runs from 1 to 66 . Hence, we have 66 regressions. For each of these regressions, we compute an pseudo $R^{2}$. In Figure 2, we depict these measures of fit against the value of $C_{i}$. We observe that the highest $R^{2}$ values are taken around $C_{i}$ equal to $5,13,24,34$ and 61 . 
In a next step, we fit the harmonic regression model with these $i=5$ cycles. The $p$-value for the joint significance in (1) of $\beta_{1,5}$ and $\beta_{2,5}$ is 0.0082 , that of $\beta_{1,13}$ and $\beta_{2,13}$ is 0.112 , of $\beta_{1,24}$ and $\beta_{2,24}$ is 0.0046 , that of $\beta_{1,34}$ and $\beta_{2,34}$ is 0.341 and finally, that of $\beta_{1,61}$ and $\beta_{2,61}$ is 0.0001 . The parameter $\alpha_{0}$ parameter is estimated as -1.222 with $p$-value 0.000 , and $\alpha_{1}$ is estimated as 0.0105 with $p$-value 0.0000 . Hence, the data show a marked upward trend. The pseudo- $R^{2}$ of this model is 0.184 . To see if these estimation outcomes are robust, we re-estimate the model by each time changing the length of one cycle, while keeping the others fixed. We observe that no improvement in fit can be obtained, so we conclude that the innovations data have cycles of length 5, 13, 24, 34, and 61 .

\section{Interpretation of the results}

In Figure 3 we depict the cycles of length 61 and 34, while in Figure 4 we present the cycles of length 24 and 13. Next, in Tables 2 to 4 we give the peaks and troughs for the three most lengthy cycles. In Table 5 and in Figure 5 we present the characteristics of the multiple cycle.

A first and obvious conclusion is that we can confirm the first hypothesis. We see that there are five cycles in the innovations series. Note that the length of these cycles also matches with the commonly found economic cycles in the literature.

The second hypothesis, which said that there is a clustering of basic innovations, seems to be confirmed by the results in Figure 5. The joint presence of five cycles in the innovations series, shows that there are sequences of years in which more (or less) innovations occurred.

The research questions formulated earlier appear to be important in the context of the critical literature review. The hypothesis that basic innovations can be decomposed in cycles has been accepted. It has also been demonstrated that clustering of basic innovations takes place. From 1917 on the clustering manifests itself around the long wave minimum and moreover it is probable that this is more at the end of the downswing than at the beginning of the upswing. To be more specific, during the 1750-1850 period the troughs in innovations match with those in the Kondratieff wave. Interestingly, from 1883 
to 1970 it is the peaks that match these troughs. Given the size of the overall sample, and the fact that there are just two cycles per 100 years, we have insufficient evidence which of the patterns will prevail in the future. The notion of the reversal of cycles seems an interesting topic for further research.

In light of the confrontation of this result with other research results it is surprising that a reverse pattern can be observed.

\section{Conclusion}

In this paper we documented the presence of a multiplicity of cycles in innovations series, a similar multiplicity as for long economic cycles. Next, we found a clustering of basic innovations. Finally, we found that in the early years the troughs in innovations match with troughs in the Kondratieff cycle, while for the second half of the sample we see a reversal, which comes closer to our a priori expectations.

For further work, we see two avenues. The first concerns the notion of the reversal of cycles, as we saw in the previous section.

The second, and quite a challenging issue, concerns the cycle lengths themselves. As we could observe from Table 1, the lengths of the cycles are remarkably close to the familiar Fibonacci numbers, which are 2, 3, 5, 8, 13, 21, 34, 55 and so on. Also, the innovations

cycles are very close. We could think of possible reasons why cycles should obey such a regularity, but we need more empirical evidence to substantiate these thoughts. 
Table 1: Cycles

\begin{tabular}{|c|c|c|}
\hline Authors & Length (years) & Driving Forces \\
\hline Kuczynski (1978) & 2 & Industrial production lag \\
\hline Kitchin (1923) & $3 ; 4$ & Inventories \\
\hline Juglar (1860) & 7 to 11 & Investments in machines \\
\hline Kuczynski (1978) & 8 & Production and export \\
\hline Kuczynski (1978) & 9 & Innovative activities \\
\hline Haustein and Neuwirth (1982) & 7 & \\
\hline Solomou (1998) & 8 to 10 & Not supported by theory \\
\hline Kuczynski (1978) & 13 & Not supported by theory \\
\hline Forrester (1977) & 14 & Bootstrap (in model) \\
\hline Haustein and Neuwirth (1982) & 13 & Not supported by theory \\
\hline Haustein and Neuwirth (1982) & 17 & Bootstrap \\
\hline Kuznets (1930) & 15 to 25 & Investment in construction \\
\hline Kuczynski (1978) & 23 & Inventive activities \\
\hline Haustein and Neuwirth (1982) & 20 & Innovation \\
\hline Solomou (1998) & 20 to 23 & Not supported by theory \\
\hline Thio (1991) & 32 & Employment \\
\hline Haustein and Neuwirth (1982) & 32 & Innovation \\
\hline Haustein and Neuwirth (1982) & 40 & Innovation \\
\hline Kondratieff (1928) & 48 to 60 & Industrial complexes \\
\hline Forrester (1977) & 50 & Capital section \\
\hline Kuczynski (1978) & 60 & Industrial production \\
\hline Goldstein (1988) & 50 to 60 & War \\
\hline Marchetti (1983) & 54 & Innovation \\
\hline Namenwirth (1973) & 48 & Culture and politics \\
\hline Berry en Kim (1994) & 48 to 60 & Generation types \\
\hline Rainer Metz (1992) & 54 to 56 & GDP series \\
\hline Howe and Strauss ( 1991 ) & 90 & Generations concept \\
\hline Namenwirth (1973) & 152 & Culture and politics \\
\hline Modelski (1978) & 140 & War \\
\hline Goldstein (1988) & 150 & Hegemony \\
\hline
\end{tabular}


Table 2: Peaks and troughs in 61-year cycle

\begin{tabular}{cc} 
Peak & Trough \\
\hline & 1788 \\
1819 & 1849 \\
1880 & 1910 \\
1941 & 1971
\end{tabular}

Table 3: Peaks and troughs in 34-year cycle

Peak Trough

$\begin{array}{ll}1784 & 1801 \\ 1818 & 1835 \\ 1852 & 1869 \\ 1886 & 1903 \\ 1920 & 1937 \\ 1954 & 1971\end{array}$


Table 4: Peaks

and troughs in 24-year cycle

\begin{tabular}{cc} 
Peak & Trough \\
\hline & \\
1768 & 1780 \\
1792 & 1804 \\
1816 & 1828 \\
1840 & 1852 \\
1864 & 1876 \\
1888 & 1900 \\
1912 & 1924 \\
1936 & 1948 \\
1961 & 1972
\end{tabular}

Table 5: Peaks and troughs in the sum of the cycles, as compared to the Kondratieff cycle (according to Goldstein, 1988)

\begin{tabular}{lccc}
\hline Peak & Trough & Kondratieff peak & Kondratieff trough \\
\hline & $1779-1802$ & 1762 & 1790 \\
$1814-1821$ & $1851-1853$ & 1814 & 1848 \\
$1883-1886$ & $1901-1904$ & 1872 & 1893 \\
$1934-1936$ & $1967-1973$ & 1917 & 1940 \\
& & & \\
\hline
\end{tabular}




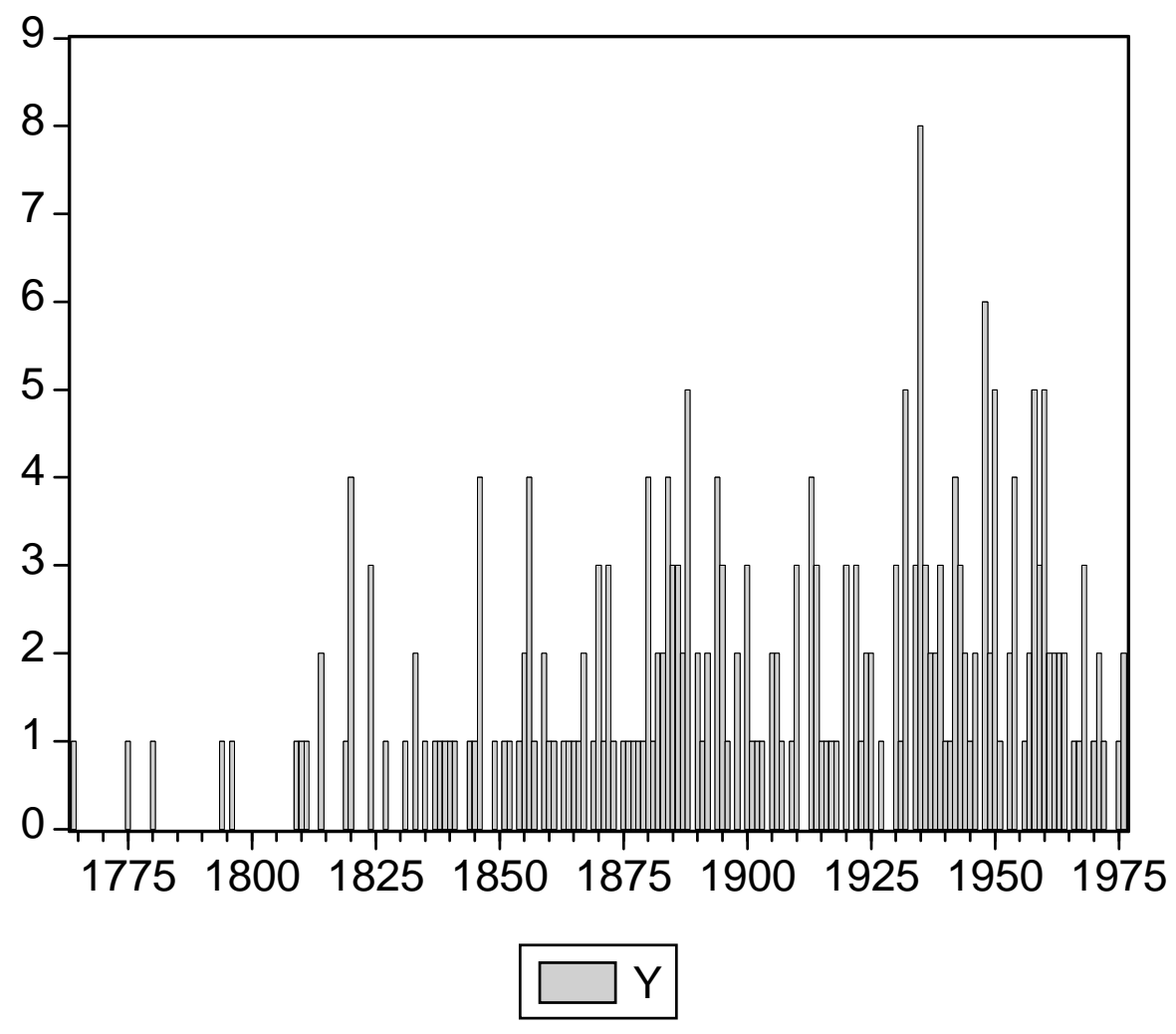

Figure 1: Time series of amount of basic innovations per year, 1764-1976 


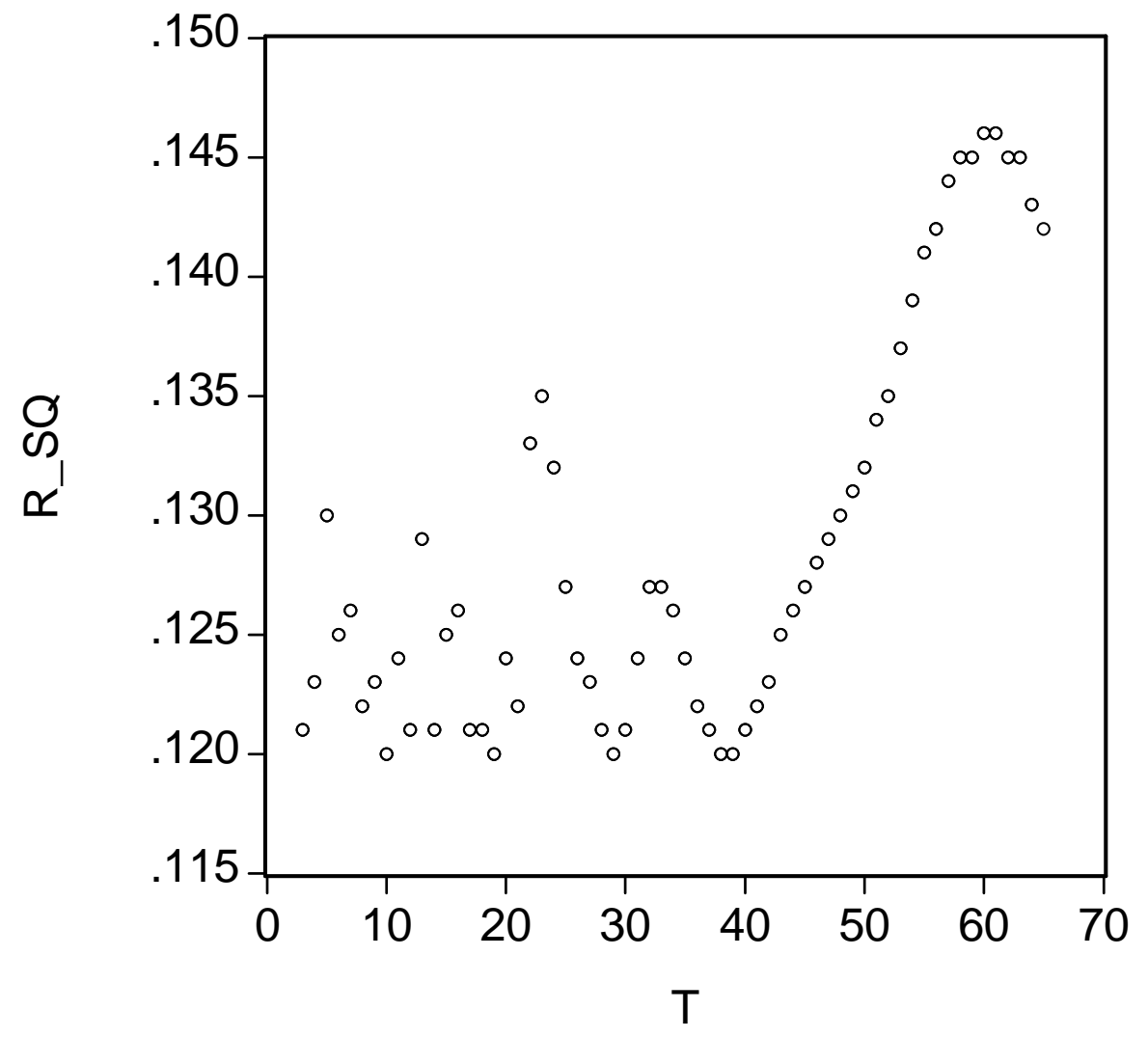

Figure 2: Partial R-squared versus cycle length in test regression 


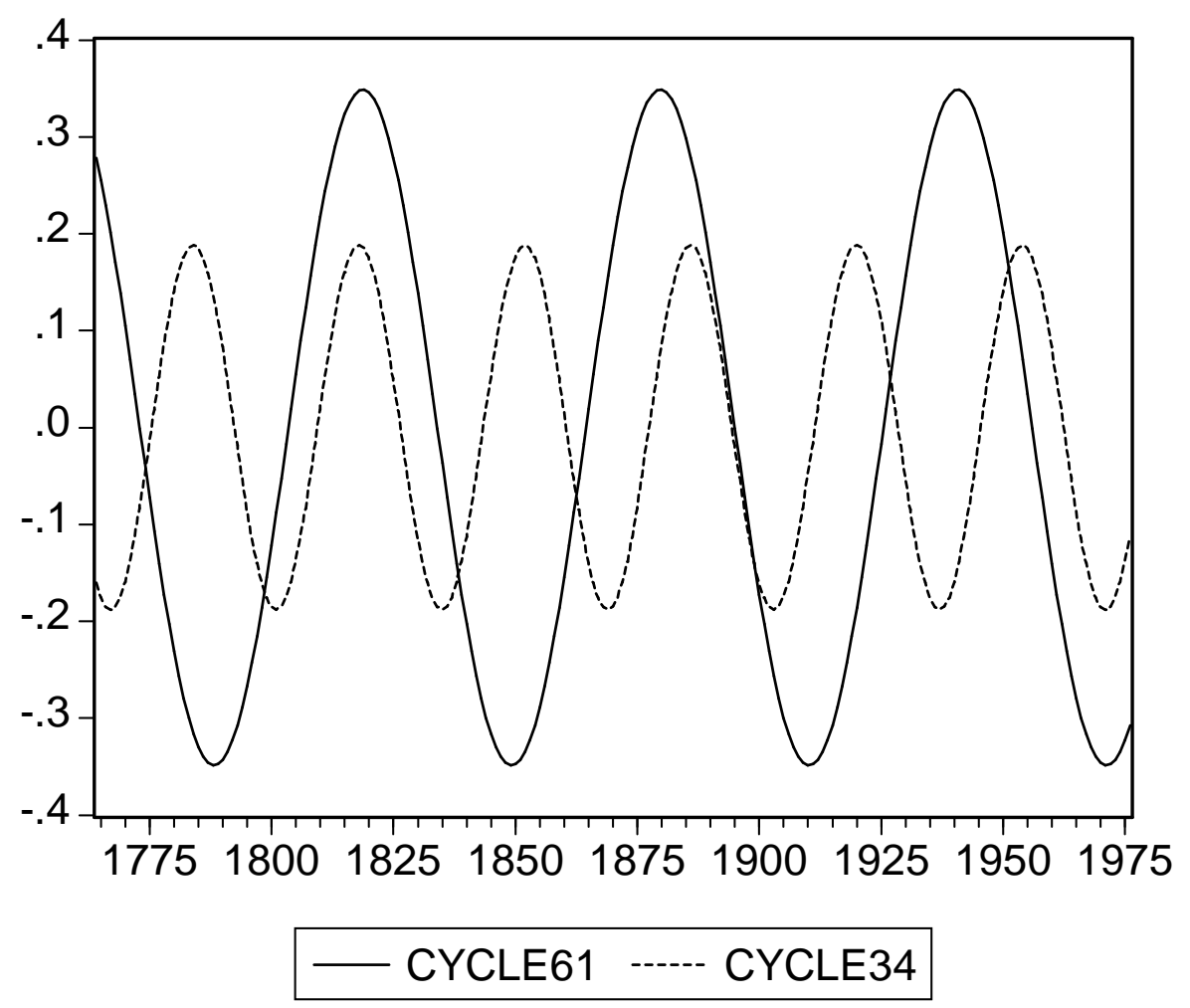

Figure 3: Estimated cycles in basic innovations data, length 61 and 34 


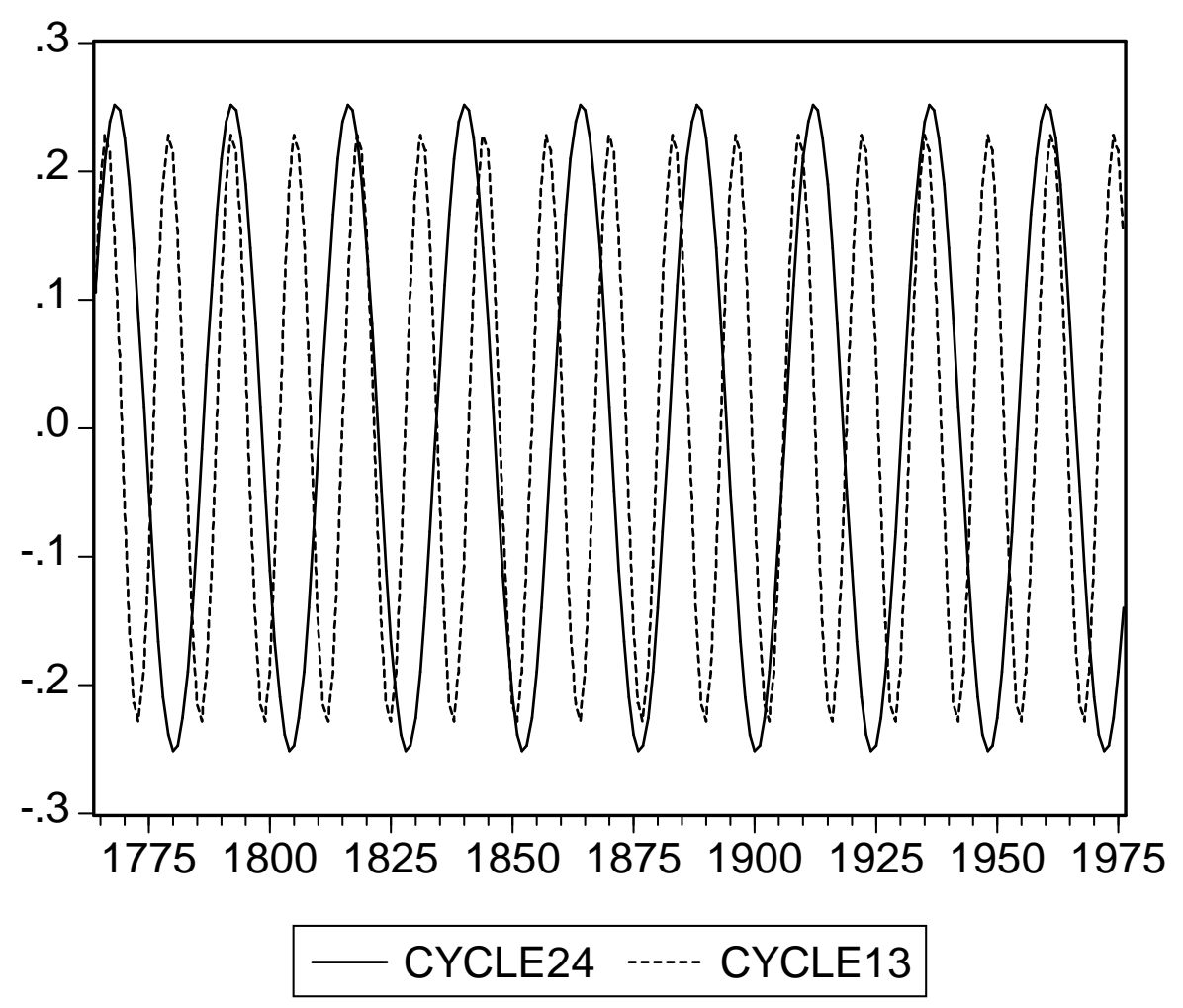

Figure 4: Estimated cycles in basic innovations data, length 24 and 13 


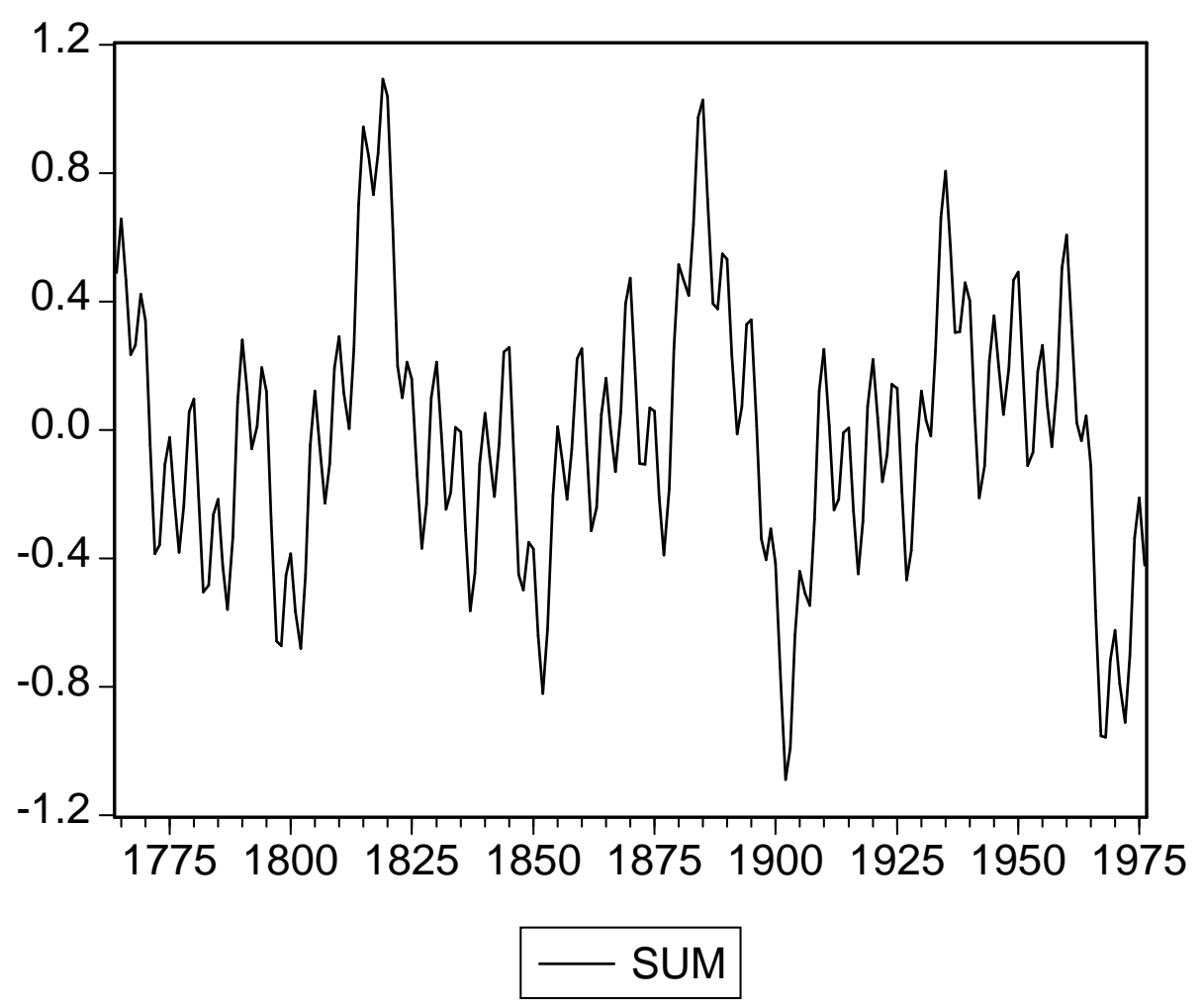

Figure 5: All cycles in basic innovations data 


\section{References}

Berry, B and H. Kim (1994), Leadership generations: A long-wave macro history, Technological Forecasting and Social Change, 46, 1-10.

Clarke, J., Freeman, C. and L. Soete (1981), Long Waves, Inventions, and Innovations, Futures, 13, 308-322.

Duijn, J.J. van (1983), The Long Wave in Economic Life, London: George Allen and Unwin.

Forrester, J.W. (1977), Growth Cycles, De Economist, 125, 525-43

Freeman, C. (ed) (1996), Long Wave Theory, Cambridge UK: The International library of critical writings in economics.

Freeman, C. and F. Louça (2001), As Time goes by. From Industrial Revolutions to the Information Revolution, Oxford: Oxford University Press.

Goldstein, J.S. (1988), Long Cycles: Prosperity and War in the Modern Age, New Haven: Yale University Press.

Haustein, H.D. and E. Neuwirth, E. ( 1982), Long waves in World Industrial Production, Energy Consumption, Innovations, Inventions, and Patents and Their Identification by Spectral Analysis, Technological Forecasting and Social Change, 22, 53-89

Hirooka, M. (2003), Nonlinear Dynamism of Innovations and Business Cycles, Journal of Evolutionary Economics 13, 549-576. 
Kleinknecht, A. (1986), Long Waves, Depression and Innovation, De Economist, 134), 84-108.

Kleinknecht, A. (1993): Recent Research on Kondratieff Long Waves, Les cahiers de l'association Charles Gilde pour l'tude de la pense conomique, 5, 171-93, reset

Kondratieff, N.D. (1935)[1925], The long waves in economic life, The Review of Economics and Statistics, 17, 105-115.

Kuczynski, Th. (1978), Spectral Analysis and Cluster Analysis as Mathematical Methods for the Periodization of Historical Processes, in Paper for the 7th International Economic History Congress, Edinburgh., pages?

Kuznets, S. (1940), Schumpeter's Business Cycles, American Economic Review, 30, 257271.

Mandel, E. (1995), Long Waves of Capitalist Development: A Marxist interpretation, London: Verso.

Mensch, G. (1979) [1975], Stalemate in Technology, Cambridge MA: Ballinger Publishing Company.

Perez, C. (1983), Structural Change and Assimilation of New Technologies in the Economic and Social Systems, Futures, 15, 357-375.

Modelski, G and Thompson, W. (1996), Leading Sectors end World Powers: The Coevolution of Global Economics and Politics, Columbia: University of South Carolina Press "

Perez, C. (2002), Technological Revolutions and Financial Capital: The Dynamics of 
Bubbles and Golden Ages, Cheltenham UK: Edward Elgar Publishing.

Schumpeter, J. (1939), Business Cycles: A theoretical, historical and statistical analysis of the Capitalist process, New York: McGraw-Hill Book Company, Inc.

Silverberg, G. and Verspagen, B. (2000), Breaking the Waves: A Poisson Regression Approach to Schumpeterian Clustering of Basic Innovations, Cambridge Journal of Economics, 27, 671-693.

Silverberg, G. (2002), The Discrete Charm of the Bourgeoisie: Quantum and Continuous Perspectives on Innovation and Growth, Research Policy, 31, 1275-1289.

Solomou, S. (1998), Economic cycles: Long Cycles and Business Cycles since 1870, Manchester: Manchester University Press.

Thio, K.B.T. (1991), On Simultaneous Explanation of Long and Medium-term Employment Cycles, De Economist, 139, 331-357.

Tylecote, A, (1992), The Long Wave In The World Economy: The Present Crisis in Historical Perspective, London: Routledge.

Wallerstein, I. (1984), Long Waves as Capitalist Process, Review, 7, 559-575 